\title{
Study on Problem of Internal Control in Chinese Commercial Banks
}

\author{
Shouchun Xiong \\ Huaiyin institute of technology, Huaian China \\ Huaian Beijing north road no. 89 \\ Xiongsc111@sina.com
}

\begin{abstract}
As an important financial institution and financial intermediary, commercial Banks are more and more concerned by the society, especially the internal control of commercial Banks. In recent years, China's commercial Banks have become more and more serious cases, which has aroused wide public concern. Weak internal control is one of the important reasons for these problems. This article takes our country commercial bank internal control as the research object, on the basis of combining the theory of internal control, to the our country commercial bank internal control present situation and the existing problems are analyzed, and advances some Suggestions on strengthening the internal control of commercial Banks in China.
\end{abstract}

Keywords-Commercial bank internal control; Control environment; Control activities; Supervision

\section{INTRODUCTION}

Standards board in the United States, in 1972, made the announcement of auditing standards, the definition of internal control is proposed as follows: "internal control is in certain circumstances, the unit in order to improve the management efficiency, obtain and use resources efficiently, achieve the established management goal, and implemented within the units of all sorts of restriction and adjustment of organization, planning, procedures and methods." And commercial Banks internal control [1] is refers to the commercial Banks to achieve its business objectives, through the formulation and implementation of a series of systems, procedures and methods, beforehand to prevent the risk, the matter controls, afterwards monitoring and corrective dynamic process and mechanism." Although 2003 joint-stock reform of state-owned commercial Banks made the internal control of commercial Banks has been significantly strengthened, but there is no denying that still exist in our country commercial bank internal control internal control environment is weak, the internal control activities is not sound, internal supervision and appraisal problems such as imperfect, triggering the theft such as firms, joint loan fraud and related transactions. Therefore, poor internal management and internal control of Banks will affect the stability and development of the entire financial system. Therefore, under the new economic and financial environment, study how to build our country commercial bank internal control system, strengthen the construction of internal control, improve the internal management level, make the commercial Banks to become "independent, self-financing" of an enterprise as a legal person, avoid and reduce due to lack of internal control of major, cases, for China's commercial Banks and the financial development has important practical significance.

\section{CURRENT SITUATION AND PROBLEMS OF INTERNAL CONTROL OF COMMERCIAL B ANKS IN CHINA}

Since this century, China's commercial Banks while the shareholding system reform, further improve the internal control effectiveness, but because of the inherent defects of internal control and internal control concepts such as the lack of a variety of reasons, there are still many problems in Chinese commercial Banks internal control, so, although our country commercial bank internal control as a whole had much better than before, but it is still relatively weak, mainly reflected in the following respects.

\section{A. Weak internal control environment}

Control environment refers to the main body of culture, values, organizational structure, management philosophy and management style, etc., is the foundation of implementing internal control, internal control environment generally includes the governance structure of commercial Banks, institutional setup and responsibilities distribution, internal audit, human resources policies, enterprise culture, etc. Controlling the environment can have a great impact on internal control. The weak control environment of commercial Banks in China is mainly reflected in the following aspects:

\section{1) Lack of internal control culture}

Internal control culture, refers to the group in the longterm practice of internal control, internal control implementation gradually formed by mutual recognition, follow, with the value orientation, moral style, ideology, the behavior way and the sum of factors such as specific material entity, internal control culture is the cornerstone of the commercial Banks internal control system, with strong support of the internal control system construction. And control environment, main show is some "soft control", however, in practice, commercial bank management ignored the internal control is a business operation in the process of interlocking, the dynamic mechanism of supervision, but the internal control shall be regarded as the rules and regulations, is superior to the day-to-day management of junior, was not aware of their own in the process of establishing and 
implementing the internal control responsibilities, this will hinder Banks improve and perfect the internal control. Such as 2005 pine river street branch of bank of China in the 1 billion disappearance of deposit, as President of the mountains, in the operation of the business in the bank, want to is how to increase their income, and the mountains of superior leadership of alpine evaluation is confined to obtain the amount of deposit, even if the mountains after taking illegal technique was found to report, leadership and ignored, as the senior management of commercial Banks, not realizing that their control in establishing and implementing the internal control environment of responsibility, this kind of mistake of ideology and value orientation is extremely unfavorable to internal control risk guard, is missing the typical performance of the commercial Banks internal control culture.

Moreover, in terms of internal control environment, internal control and business development contradictory thoughts, one-sided pursuit of business expansion, ignore the risk control, ignore the personnel moral hazard, there is "money in the bank is the country's", not only enterprises, departments and local party and government departments a lot of people think so, even the bank of China, some of the cadres and workers are also think so. The bank's assets are regarded as state-owned assets, and the bank's money is regarded as the surname "gong", which is the ideological root cause of nonperforming loans in Chinese Banks. Taking bank money as the state's money, ignoring risk control, and ignoring the correction of ideas has led to a lot of suspicious lending. In addition, the non-performing loans in the secondary class of non-performing loans, the secondary class balance of nonperforming loans also showed a trend of rising year by year, the commercial bank staff should also due diligence investigation, evaluation, review, collect, for low-income, minority, the low level of education, family and personal financial knowledge is scarce seriously review their credit standing. It is because of internal control and business development contradictory thoughts, commercial Banks related staff one-sided focus on performance evaluation and business expansion, resulted in the increasing of nonperforming loans, this is also indirectly reflects of weak internal control culture.

\section{2) The internal governance structure is not perfect}

The modern corporate governance structure consists of four parts: the shareholders' meeting, the board of directors, the board of supervisors and the executive organization composed of senior managers. Among them: the general meeting of shareholders is the supreme authority of the company, it is composed of all shareholders, make decisions on major issues of the company, has the right to selection and remove directors, responsible for the supervision and inspection of the stock market's financial and business execution conditions; The board of directors is the highest decision-making structure of the company. It is responsible for the examination and approval of the overall business strategy and major policies of commercial Banks, and has the employment, rewards and punishments and dismissal rights for senior managers. Board of supervisors is responsible for a comprehensive understanding of the risk management of commercial Banks, tracking supervision of the board of directors and senior management for perfecting the internal control related work, inspection and investigation in the daily business activities whether there is any violation of the established risk management policies and principles; Senior management, be responsible for the executive board approved the strategies, policies, systems and procedures, is responsible for establishing clear authority and responsibility, report relationship clear organizational structure, establish risk identification, measurement and management procedures [2].

However, in the internal control of commercial Banks in our country, as the highest decision-making body of the board of directors often did not work out suitable for the development of the bank management strategy, confined to the current business needs, not according to the actual situation of financial markets, for the future of the Banks from the perspective of long-term development strategy [3]. It is unreasonable to pay attention to the performance appraisal and business expansion of senior managers and ignore their moral hazard. Do not pay enough attention to the supervision of the audit of the board of supervisors, the supervision of the operation and management of the company did not conduct a comprehensive, investigation and review the company's business situation, financial situation has only become a mere formality, for given by the board of directors of the planning, decision-making and supervisory board without the continuous tracking supervision and correct. In addition, the supervisory board has not implemented effective supervision over the behavior of cadres at all levels. For example, the board of supervisors will not be able to timely point out when the directors have made improper nominations and hired senior management personnel. Is not very good effective internal governance structure is another reason why "inside ghost collusion", the board of directors and board of supervisors and senior managers not only carry out their duties without due diligence, collusion, collude with, damage the interests of the bank [4].

\section{B. The control activity is not sound}

Control activities refers to the combination of specific business and matters, using the relevant control policies and procedures, or the control means to control and control measures include: general incompatible duties separation control, authorization, approval control, accounting system control, property protection control, budget control, operation control, performance evaluation, control and so on. In this paper, the "incompatible position separation control" of control measures is studied. The so-called incompatible position refers to the position that if one person holds the job, it can be both wrong and corrupt, and it can cover up the mistakes and abuses. Incompatible duties separation is the core of "internal check", it requires that each economic business, it takes two or more departments or personnel processing, making the work of a single person or department must be consistent with other people or department work or associated with, and subject to the supervision and restraint. The establishment and implementation of the internal control system must implement the principle of incompatible duties of duty. However, in our country commercial bank in the actual operation of the internal control, we did not need separation 
incompatible duties, use of part-time job, mutually corrupt collusion, embezzlement, theft of bank assets. In 2007, there were nearly $51 \mathrm{~m}$ cash stolen cases in the bank of handan agricultural bank. The suspects, ren xiaofeng and ma, stole nearly 51 million cash from agbank's coffers. We know that in the management of bank Treasury, the key and password of the Treasury, the cash deposit and the bookkeeping are all typical incompatible positions. Ren xiaofeng also holds the key of the Treasury and opens the password, while ma xiangjing also holds the cash custody and accounting work, providing the convenience for them to commit crimes. Thanks to control activities in the incompatible duties cannot be effective separation, containment, fraud in a while, led to cases such as the embezzlement, makes the serious financial institutions and almost harsh control measures at the bank.

\section{Internal supervision and review are not perfect}

Commercial Banks internal supervision system should be constantly in the daily work of supervision and review of bank internal control overall effect, the supervision of the main risk assessment should be a part of bank's daily activities, for all levels of management and internal auditors should also comment on a regular basis. In addition, the internal control system should carry out effective and comprehensive internal audit, internal audit should be conducted independently, and should be carried out by trained and competent personnel. Internal audit as part of the supervision and review internal control system, shall be subject to the supervision of the audit committee, or on a regular basis should be required to the board of directors and the audit committee and board of supervisors, senior management report directly.

Commercial Banks in China, however, in actual operation, the internal supervision and management of internal audit is not to implement effective daily production and business operation activities, the comprehensive audit, internal audit personnel in the supervision and inspection found that the problem, not to the board of directors or the management opinions were put forward. In addition, the internal auditors to audit found in violation of state laws, regulations and business matters prescribed by the articles of association does not give the correct audit opinion, but despise external audit institutions audit opinion, audit regulation failure cause. Moreover, part of the number of commercial Banks in our country from internal audit supervision and not give enough attention, can appear even collude with "inside ghost" do not cooperate with audit check phenomenon, and the bank on the problems found during the audit check after put forward rectification opinions, many remain in the file or verbally, continuous supervision and rectification and tracking check does not reach the designated position, these conditions can affect the authority of the internal audit. At the same time, the branches as functions of the internal institutions at the same level, audit department personnel, wages, benefits, etc. By this line at the same level management, internal audit department in carrying out audit work is vulnerable to this unit the leadership of intervention, difficult to maintain relative independence.

\section{STRENGTHEN THE INTERNAL CONTROL STRATEGY OF COMMERCIAL BANKS IN CHINA}

In view of the existing in the internal control in commercial Banks internal control environment is weak, the internal control activities is not sound, internal supervision and review of such problems as incomplete, and start from the case of caused by these problems, puts forward some Suggestions, including: to create a good internal control environment, the construction of strengthening internal control measures, establish a comprehensive system of supervision and inspection.

\section{A. Strengthen internal control environment construction}

Firstly, the internal control consciousness of the whole staff should be enhanced. Employee's integrity level and the level of professional ethics is an important influence factors of internal control, commercial bank leaders at all levels must first fully understand on thought to establish a sound internal control is a necessary choice to guarantee the healthy operation and development bank, aware of their own in the process of establishing and implementing the internal control responsibilities, really attaches great importance to the construction of internal control; Second to pay special attention to the publicity and education on employees' internal control consciousness, lead employees to abandon the "business development and internal control contradictory" thought, strengthen the consciousness of all staff of the internal control, again want to establish the authority of the internal control mechanism, guarantee the implementation of all internal control system and effective implementation.

Secondly, the internal control structure of commercial Banks should be improved. Commercial Banks should adhere to the joint-stock reform, formed in the internal commercial Banks "shareholders' meeting, board of directors and board of supervisors, managers," the corporate governance structure, build system of independent director system, external supervisors, establishing rules of procedure and decisionmaking procedures, clear the board of directors and directors and board of supervisors and senior managers and supervisors, and senior management of the internal control duties and responsibilities. As the highest decision-making body of the board of directors according to the actual situation of the financial markets to develop a suitable for the development of the bank management strategy, focus on senior managers ethical quality, to develop appropriate senior managers to hire, rewards and punishment mechanism. Commercial Banks in the specification of the board of directors at the same time should pay attention to ensure enough independence of the board of supervisors to give full play to the role of the board of supervisors, board of supervisors should keep a certain number of the members have the professional quality of all aspects of the corresponding external supervisors, investigation and review the company's business situation, operation and management of the company to conduct a comprehensive supervision, ensure timely and accurately find the director and the management of errors or irregularities. 


\section{B. Strengthen control activities}

Firstly, the separation of post control and responsibility should be strengthened. In the capital business of commercial Banks, the former, middle and backstage separation, namely the front desk transaction, the central Taiwan risk control, the background fund liquidation position separation; To separate the pre-loan investigation and loan review in the credit loan business; The separation of warehouse keeper and teller in bank accounting. In general, the division of responsibilities and position of commercial Banks should establish three supervisory lines on the basis of mutual supervision and interconnection, namely, the establishment of double check system; Establish a complete business process; Establish an internal supervision department to strengthen all aspects of the business, and implement comprehensive supervision of each business department.

Secondly, the authorization management system should be improved. Our country commercial bank should strictly abide by the principle of "unified management, grading is responsible for", through the standardization of authorization form, such as the unified rules and regulations and measures for the administration of authorization management, clear authorization management content and working procedure, improve the authorization management system, to form a clear division of responsibilities, clear responsibilities of decisionmaking system. The scope of authorization shall cover the business of credit, finance, finance, accounting and settlement, etc. The content of authorization may include: clearly define the rights of the board of directors and the executive level; clarify the authority of different levels of staff of different businesses and so on. At the same time, after making the specification, it should also pay attention to periodically checking the authorization of branch offices to prevent unauthorized privileges or improper authorization.

\section{Establish and improve internal control and supervision}

First, establish a vertical independent internal audit system. Commercial Banks should be vertical and relatively independent internal audit system, for example: undo each affiliated branches of internal audit department, set up regional centers of audit, is not subject to the jurisdiction of the local bank; The salary and welfare benefits of the audit department staff are not subject to the management of the same level, and maintain the independence and authority of the audit.

Secondly, the quality of internal auditors should be improved. Auditing department should be "people-oriented" management concept, and fully mobilize and exert the potential of each audit, put the right person in the appropriate business areas and projects, and strive to improve the internal auditor's responsibility, risk awareness, responsible for the bank, responsible for the public; Realize audit resource sharing, establish internal audit expert information base and audit case, audit knowledge database, improve internal audit quality; Targeted and targeted to strengthen the training of auditors, training professionals with rich knowledge structure and high level of professional skills.

Third, transfer audit strategy center, innovative audit means. The strategic focus of the audit should be transferred to comprehensive risk management and integrated operation management. The audit mode will be changed from the audit department to the management. The focus of the audit should shift from inspection and supervision to analysis and evaluation. At the same time, the application of traditional manual audit methods off-site audit, by means of computer technology, through the computer network real-time and batch processing of the auditees related business information, reduce the on site audit paper certificates of borrowing; Facilitate the sampling of auditors; Convenient location of some abnormal items, improved efficiency.

Finally, establish an industry self-discipline supervision mechanism. Banking association in supervision and constraint each other each other, promote the communication and exchange, supervise and urge self-discipline, standardize management, between the industry, strengthen the cooperation among member units, build a good financial environment, the risk prevention to the lowest, establish and improve internal control system.

\section{CONCLUSION}

From the description and analysis of this article, you can see that although at present our country commercial bank internal control system construction has made great development, joint-stock reform of commercial Banks are also gradually, has basically formed the restraining each other, mutual supervision and internal control mechanism, but there are still some problems to be solved, specific displays in: weak internal control environment, including: lack of internal control culture; Internal governance structure is imperfect; Internal control activities, etc

According to the above problem, this paper puts forward Suggestions of perfecting our country's commercial Banks internal control: first, to create a good internal control environment, enhance the overall sense of internal control, perfect the governance structure of the commercial Banks internal control; Second, the construction of strengthening internal control measures, strengthen the position control and separation of duties, improving the authorization management system; Third, the establishment of a comprehensive supervision and inspection system, the establishment of vertical independence of internal audit, improve the quality of the internal auditors, the transfer audit strategy center, innovative means of audit, establish industry self-discipline supervision mechanism.

\section{REFERENCES}

[1] China banking regulatory commission. Internal control guidelines for commercial Banks, 2006.

[2] Song liang-rong. Internal control of banking financial institutions. First edition. Shanghai: lixin accounting press, 2010.

[3] Cui honghong. Research on internal control problems of urban commercial Banks based on full investigation: [dissertation], lanzhou: lanzhou university, 2013.

[4] Zhao kening. Internal research of commercial Banks based on management perspective: [dissertation], Beijing: Beijing university of chemical technology, 2013. 